Open Access

\title{
Erratum to: Barriers to women's representation in academic excellence and positions of power
}

Rizwana Yousaf ${ }^{1 *}$ and Rudi Schmiede ${ }^{2}$

* Correspondence: rizwana.yousaf@stud.tudarmstadt.de; rizwanayousaf@hotmail.com ${ }^{1}$ Technische Universitaet Darmstadt, Hoelderlinweg 22, 64285 Darmstadt, Germany

\section{Erratum}

After publication of this article (Yousaf and Schmiede 2017), a spelling error was noticed in the article title, a sentence in the article Abstract and in one of the headings of the body of the article.

The article title originally read "Barriers to women's underepresentation in academic excellence and positions of power". This has been corrected to "Barriers to women's representation in academic excellence and positions of power" in this erratum and also in the original article (Yousaf and Schmiede 2017).

In the article abstract, the sentence "Regions and countries may vary in term of culture, achievements and development, but barriers for women's underrepresentation in academia are surprisingly similar in many regions" has been corrected in the original article (Yousaf and Schmiede 2017); "underrepresentation" has been replaced with "representation".

In addition to this, one of the main headings in the article body was corrected in the original article (Yousaf and Schmiede 2017) from "Barriers of underrepresentation at academic excellence and position of power" to "Barriers to women's representation in academic excellence and positions of power". The original article was corrected for these three errors.

\footnotetext{
Author details

${ }^{1}$ Technische Universitaet Darmstadt, Hoelderlinweg 22, 64285 Darmstadt, Germany. ${ }^{2}$ Technische Universitaet Darmstadt, Technische Universität Darmstadt, Institut für Soziologie (über Empirische Sozialforschung, Karolinenplatz 5 64283 Darmstadt, Germany.

Received: 6 March 2017 Accepted: 6 March 2017

Published online: 20 March 2017

\section{Reference}

Yousaf, R., and R. Schmiede. 2017. Barriers to women's presentation in academic excellence and positions of power. Asian J Ger Eur Stud 2: 2. doi:10.1186/s40856-017-0013-6.
} 